\title{
Retinal Pigment Epithelium Adenoma and Adenocarcinoma: A Review
}

\author{
Janani Sreenivasan ${ }^{a}$ Pukhraj Rishi $^{a} \quad$ Kalpita Das $^{a}$ \\ Subramanian Krishnakumar ${ }^{b}$ Jyotirmay Biswas ${ }^{b}$ \\ aShri Bhagwan Mahavir Vitreoretinal Services, Chennai, India; ${ }^{\text {b } L \& T ~ O c u l a r ~ P a t h o l o g y ~ D e p a r t m e n t, ~ V i s i o n ~ R e s e a r c h ~}$ \\ Foundation, Chennai, India
}

\section{Keywords}

Eye · Tumour · Malignancy · Retina - Retinal pigment epithelium · Adenoma - Adenocarcinoma - Uveal melanoma . Biopsy $\cdot$ Pathology $\cdot$ Enucleation

\begin{abstract}
Adenoma and adenocarcinoma of the retinal pigment epithelium (RPE) are rare intraocular tumours that are often misdiagnosed as posterior uveal melanoma or other simulating lesions. It is important to be able to differentiate these tumours from melanoma for 3 reasons. First, an inability to rule out melanoma often tilts the management towards enucleation. Second, management options like radiotherapy and local resection which work well for melanoma may not be easily applied to these tumours. Third, and most importantly, patients with melanoma need a lifetime follow-up to rule out metastases (metastatic dormancy) whereas RPE tumours hardly metastasize. An abruptly elevated, often deeply pigmented tumour, with a prominent retinal feeding artery and a draining vein causing exudation, should raise a suspicion of RPE tumours. RPE tumours have a remarkable local invasive potential but a low metastatic potential. Most RPE tumours require treatment due to local complications. Small, asymptomatic tumours can be generally observed. Enucleation is still the gold standard of treatment, although local
\end{abstract}

resection has been reported in selected cases with good results. Here, we provide a comprehensive review of the demographic, clinical, and imaging features of true acquired neoplasms of the RPE, namely adenoma and adenocarcino$\mathrm{ma}$, the ways to differentiate them from melanoma, their clinical course and prognosis, and Options for their management.

(c) 2020 S. Karger AG, Basel

\section{Introduction}

The retinal pigment epithelium (RPE) and the uveal melanocytes are the 2 melanin-bearing cells of the eye, and they differ strikingly with respect to their proliferative disorders [1]. Uveal melanocytes, which give rise to malignant melanomas, rarely undergo reactive proliferation whereas the RPE exhibits a marked tendency for reactive proliferation, but true neoplasms are rare [1]. True acquired neoplasms of the RPE, namely adenoma and adenocarcinoma, are rare lesions that can simulate choroidal melanoma and, historically, have led to enucleation [2]. Both conditions are typically pigmented and appear as a solid mass in the posterior segment of the eye, but several features differentiate them clinically from melanoma, including abrupt elevation, a prominent retinal karger@karger.com

(c) 2020 S. Karger AG, Basel

www.karger.com/oop

Karger ${ }^{\prime}=$
Pukhraj Rishi

Shri Bhagwan Mahavir Vitreoretinal Services

Sankara Nethralaya, 18 College Road

Chennai 600006 (India)

docrishi@yahoo.co.in 


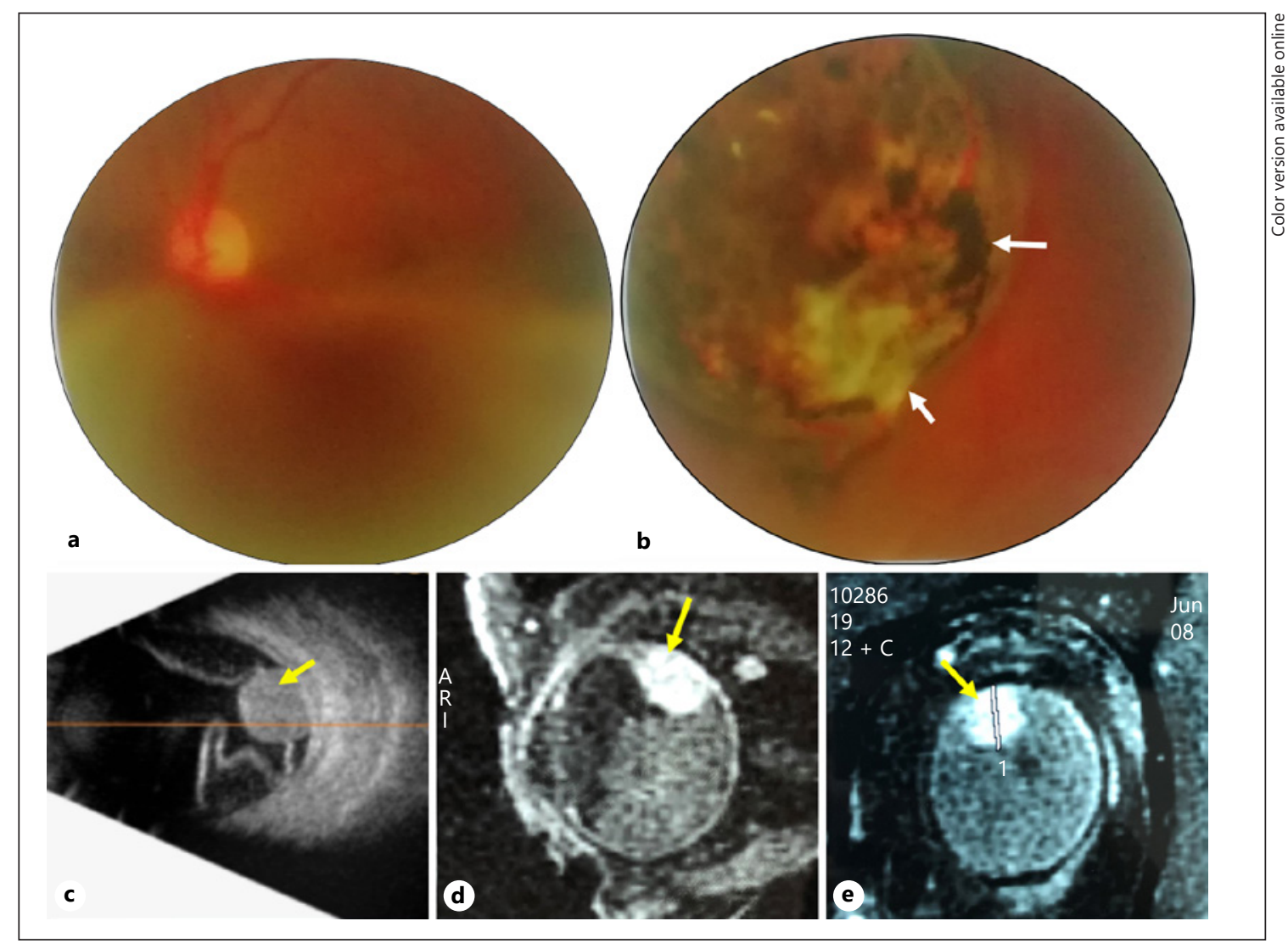

Fig. 1. Fundus photo (a) of the left eye shows exudative retinal detachment in the sitting position and retinochoroidal tumour (b, white arrows) with surface metaplasia and pigmentary changes in the superonasal quadrant. c Ultrasound reveals total retinal detachment with a retinochoroidal mass lesion noted in the supero- nasal quadrant (yellow arrow) with high surface reflectivity and medium internal reflectivity with choroidal excavation. d MRI shows dome shaped intraocular lesion in the superonasal quadrant (yellow arrow), hypointense in T2 and hyperintense in TIWI with enhancement after IV contrast (e, yellow arrow). feeder vessel, and related exudation with RPE tumours compared to the dome or mushroom configuration and serous retinal detachment that come with melanoma [24]. Melanoma is a far more perilous condition with the risk of metastasis; in RPE tumours, metastatic disease is uncommon [4]. Thus, it is important to recognise RPE tumours and differentiate them from uveal melanomas, due to diverse implications for prognosis and follow-up. Here, we present a comprehensive review of the demographic features, clinical aspects, pathogenesis, investigations, natural course, differential diagnosis, pathology and management of this rare intraocular tumour, exemplified with a description of a low-grade RPE adenocarcinoma in a young Asian male that was referred to us as a case of malignant melanoma of the choroid.

\section{Methodology of Literature Search}

Literature selection for this review was done in the databases of PubMed, Ovid MEDLINE, and Google Scholar, using the keywords: (Retinal pigment epithelial adenocarcinoma), (Retinal pigment epithelial adenoma), (Retinal pigment epithelial tumours), (Pigmented lesions of fundus), (pseudomelanoma), (intraocular tumour), and (Retinal pigmented epithelium) for the period 1970 to March 2020. It revealed around 100 articles, most of them case reports and a few original studies. Out of these, 70 pertinent articles from the English language literature were selected for the study.

\section{Case Report}

A 33-year-old apparently healthy male of Asian descent presented with the complaint of gradually progressive diminution of vision in the left eye of 3-year duration. He was diagnosed elsewhere as having a choroidal melanoma and referred to us for further management. On examination, the right eye was essentially normal with a best-corrected visual acuity (BCVA) of 


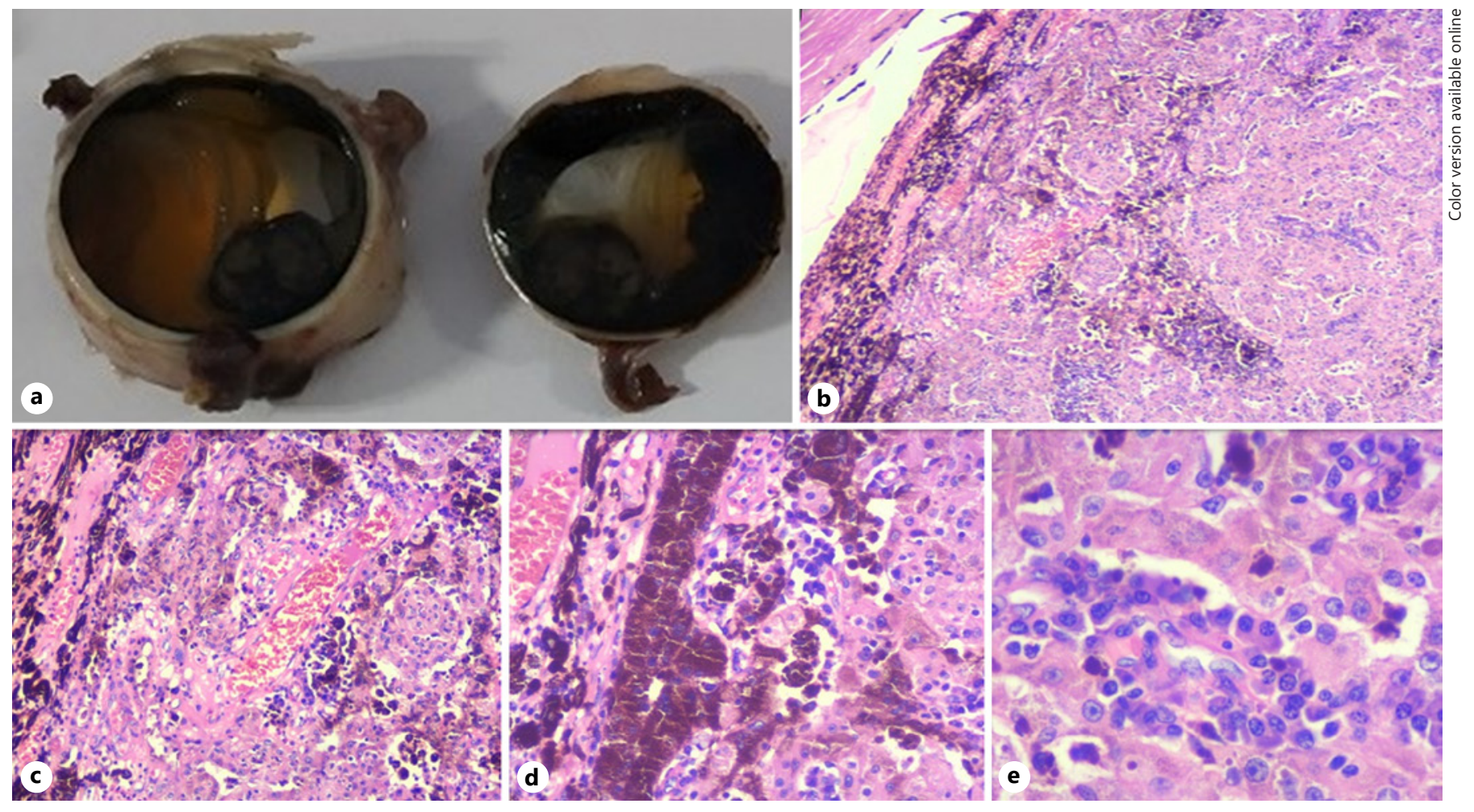

Fig. 2. a Photograph of the grossly sectioned globe showing pigmented mass lesion in the superonasal quadrant. b-e Photomicrographs. b Partially pigmented tumour, arising from the RPE with retinal invasion. $\times 100$. Cells arranged in a lobular (c) and a glandular pattern (d). $\times 200$. e Round-to-oval cells with prominent nucleoli and mild pleomorphism. $\times 400$.
20/16, while the left eye had nil light perception (NLP). On examination, the anterior segment of the left eye was unremarkable. Fundus examination (Fig. 1a) revealed a bullous, exudative retinal detachment with a pigmented tumour, about 5 disc-diameters in size, in the superonasal quadrant. A provisional diagnosis of uveal malignant melanoma was entertained. Ultrasound (Fig. 1b) revealed a retinochoroidal mass lesion with high surface reflectivity, moderate internal reflectivity, and measuring $7.85 \mathrm{~mm}$ (horizontal basal diameter) $\times 5.33 \mathrm{~mm}$ (height) $\times 7.23$ $\mathrm{mm}$ (vertical basal diameter). Magnetic resonance imaging (MRI; brain and orbits) showed normal brain parenchyma and a dome-shaped intraocular tumour, hypointense in T2 and hyperintense in T1 with contrast enhancement (Fig. 1c, d). Metastatic work-up with ultrasound of the abdomen, liver function tests, and chest X-ray were unremarkable. Ultrasound and MRI features were suggestive of uveal melanoma and the patient underwent enucleation. Histopathology revealed a dome-shaped pigmented tumour arising from the RPE showing cells arranged in a cord-like trabecular and glandular pattern (Fig. 2), with chronic inflammatory cells in the choroid but without choroidal invasion. The individual tumour cells were round-to-oval, with a high nucleic/cytoplasmic ratio and melanin pigmentation. The tumour was predominantly protruding into the vitreous cavity with retinal invasion. Nevoid cells were absent, ruling out melanoma. Further studies with immunochemistry (IHC) showed immunoreactivity (Fig. 3a-d) strongly for epithelial membrane antigen (EMA; a common epithelial marker) and HMB-45 (a melanocyte marker), but weakly for SOX-10 (a melanocyte marker) and cytokeratin (CK)-AE1/E3 (an epithelial marker), and a Ki-67 index (a marker of cellular proliferation) of 1\%. Based on histopathology and immunoreactivity, a diagnosis of low-grade RPE adenocarcinoma was arrived at.

\section{Literature Review}

\section{Demographic Features \\ Incidence}

True acquired neoplasms of the RPE are rare [2]. Saeed et al. [5] performed a review of the results for 297 enucleation, evisceration, and exenteration specimens submitted over a 20-year period in a tertiary eye-care set-up; they reported the incidence of RPE adenocarcinoma to be $0.35 \%$. However, there was no data on the incidence of RPE tumours in the general population as such. 

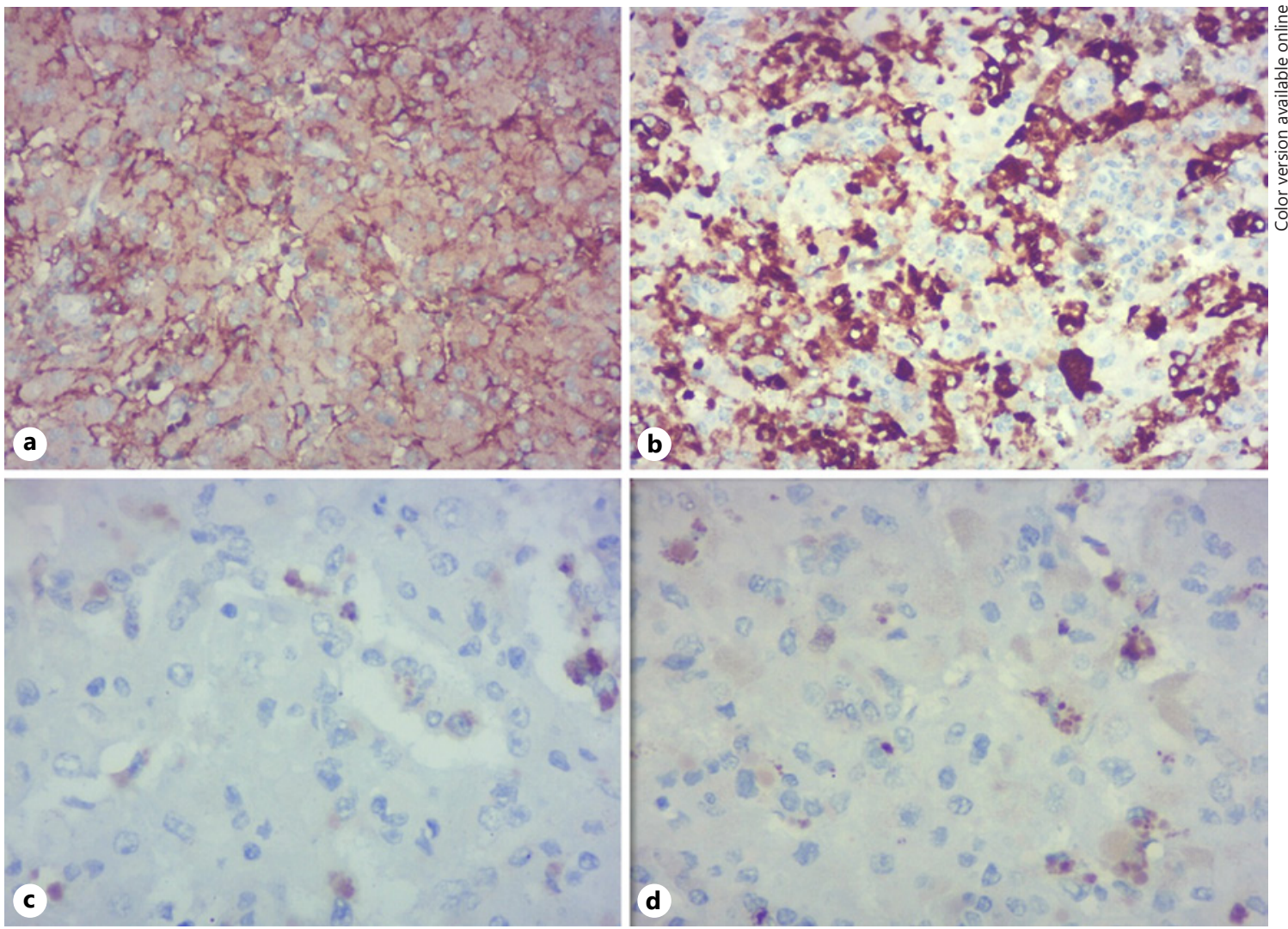

Fig. 3. Photomicrograph of immunohistochemistry using special stains: strongly positive for EMA $(\mathbf{a} ; \times 200)$ and HMB-45 (b; ×200) but weakly positive for SOX-10 (c; ×400) and Ki-67 (d; ×400).

Age

Shields et al. [3] reported that the mean age at diagnosis in their series of RPE tumours was 53 years and Williams et al. [2] reported a median age at diagnosis of 52 years in their recent large series.

\section{Race} [2].

There appears to be no specific predilection for race

\section{Sex}

There appears to be a slight female preponderance, as shown by Shields et al. [3] and Williams et al. [2]. However, isolated case reports have been reported in male patients as well [6-10].

\section{Pathogenesis and Nomenclature}

Acquired neoplasms of RPE can be considered to evolve as a disease-spectrum according to Shields et al. [3] and Tso and Albert [1]. At one end are the true neo- plasms (adenoma/adenocarcinomas) which are relatively small, discrete tumours in otherwise-normal eyes, with clear media and no history of disease or trauma [1]. At the other end of the spectrum are reactive nodular proliferative lesions that are typically observed on routine histopathologic study after enucleation of painful blind eyes, with opaque media and a long-standing history of old disease or injury [1]. In the middle of the spectrum, there are lesions for which no clear distinction between hyperplasia and true neoplasms can be made, either clinically or histologically [11]. It has been acknowledged that RPE tumours can arise from reactive hyperplasia and metaplasia following trauma, inflammation, or degenerative processes that involve the choroid or retina [12]. They have been reported to arise from congenital hypertrophy of the retinal pigment epithelium (CHRPE) as well [13-18]. Hence the characterisation of primary (arising de novo) and secondary (arising from pre-existing lesions) RPE tumours [19]. Although adenoma and adenocarcinoma of the RPE 
have also been described as benign and malignant epitheliomas [16], RPE adenoma and adenocarcinoma are the preferred terms.

\section{Clinical Features}

\section{Laterality}

RPE tumours are almost always unilateral. None of the cases reported in the literature were bilateral. Precursor lesions like CHRPE can be bilateral [18].

\section{Presenting Symptoms}

The most common presenting symptoms are a gradual diminution of vision [2], followed by floaters [12, 20, 21]. Small peripheral tumours may be asymptomatic and detected at a routine eye check-up.

\section{Anterior Segment Findings}

Shields et al. [3] reported signs of uveitis like posterior synechiae and cells in the anterior vitreous face or, less commonly, in the anterior chamber. Vitreous cells are more common in RPE tumours as they arise internally to Bruch's membrane [3]. Finger et al. [22] suggested that one should suspect RPE adenocarcinoma when a woman presents with a pigmented intraocular tumour and signs of ocular inflammation.

\section{Posterior Segment Findings}

Precursor Lesions/Ocular Associations

Many cases of RPE adenoma/adenocarcinoma have been reported to arise from CHRPE [13-18]. The RPE tumours arising from CHRPE can vary from an elevated nodule to large mass lesions, acquiring a retinal feeder vessel and causing exudation [13-18]. CHRPE with or without adenoma can cause remote macular complications like cystoid macular edema (CME) and epiretinal membrane (ERM) [13, 23]. Adenocarcinoma associated with CHRPE is variably managed with local resection [14, 15], enucleation [16], and proton-beam therapy followed by local excision [17]. RPE tumours have been reported to arise from RPE hyperplasia, in the setting of post-inflammatory scars $[2,19,24]$, scarred choroidal neovascular membrane (CNVM) [10], and painful blind eyes [5, 7, $8,25-27]$. All these conditions have one common denominator, the abnormal proliferation of the RPE incited by various stimuli. One case of RPE adenocarcinoma was detected on histopathology in an eye enucleated for late recurrence of retinoblastoma (RB; bilateral, the other eye was enucleated) with metastases [28]. The authors postulated that an unsuspected RPE tumour arising from RPE hyperplasia occurred secondary to the focal treatment of
$\mathrm{RB}$, or that both tumours arose from reactivation of a common cancer stem cell, or that changes in the microenvironment related to the development of RPE adenocarcinoma permitted the exit from dormancy of an RB cancer stem cell [28]. Fiorentzis et al. [29] reported a case of an RPE adenoma imitating a malignant transformed melanocytoma at the optic nerve, 10 years after treatment of a peripheral choroidal melanoma in the same eye.

\section{Tumour Description}

Colour

RPE tumours are often deeply pigmented but can be amelanotic as well. Pigmented tumours are easily mistaken for melanoma [2, 3]. Amelanotic tumours have been misdiagnosed as choroidal haemangioma [30] or macular CNVM [31].

\section{Contours}

Most of the tumours are abruptly elevated [2-4] but they can be dome-shaped as well.

\section{Size}

RPE tumours are variable in size. Published reports have described them as being as small as a flat nodule [13] arising from the CHRPE, or as large as 7-disc diameters in size [32].

\section{Location}

The most common location of these tumours is the periphery $[2,3]$. However, they have also been reported at a juxta-papillary location $[33,34]$ where they can simulate melanocytomas or melanomas, and in the macula simulating a CNVM [31].

\section{Surface Changes}

The most common tumour surface change reported is a small speck of haemorrhage $[24,32]$. There are no reports of orange pigment on the surface as seen in melanoma.

Feeder Vessels

A particularly important feature of RPE adenocarcinoma is the occasional presence of a dilated retinal feeder vessel [12]. Shields et al. [3] found dilated retinal vessels in 8 of 13 RPE tumours in their study, which were accentuated on fluorescein angiography.

Surrounding Retina

RPE tumours are known to cause a yellowish subretinal exudate $[2,3]$. They can be associated with exudative 
retinal detachment, but less often than melanoma. They can cause macular complications like CME, surfacewrinkling maculopathy, macular pucker, or, rarely, a macular hole $[13,35]$. Other features include vitreous haemorrhage [3] and subretinal gliosis [9].

\section{Systemic Features}

Usually, RPE tumours do not cause systemic metastases unless there is extraocular extension [20]. But when an RPE tumour is detected accidentally on histopathology, after evisceration or enucleation for a painful blind eye with opaque media, it is prudent to exclude the possibility of a secondary adenocarcinoma with possible primary sites like the lung, breast, or kidney [6]. On the other hand, there have been reports of RPE tumours being detected along with systemic malignancy, one with bronchogenic carcinoma [6] and the other with glioblastoma multiforme [34], most likely a coincidental association. In their study on transgenic mice, Penna et al. [36] showed RPE tumours to be capable of metastasising to the spleen and inguinal lymph nodes.

\section{Investigations}

Ultrasound

RPE tumours are usually abruptly elevated (a Derbyhat appearance) or dome-shaped, with high (the most common) or medium internal reflectivity, and acoustic solidity $[2,3]$. On ultrasound, tumour dimensions can be measured, and any associated retinal detachment can be detected.

Fundus Fluorescein Angiography

Williams et al. [2] observed in their series that RPE tumours exhibited early hypofluorescence and late hyperfluorescence with staining or leakage. The feeding retinal artery and the draining vein may be highlighted by fundus fluorescein angiography (FFA) [31]. Ramahefasolo et al. [9] discussed the correlation between clinical, FFA, and histopathological examination (HPE) findings in their report. They showed that the more pigmented part of the tumours showed hypofluorescence throughout the FFA study, with densely packed tumour cells and less stroma in HPE, and vice-versa [9].

\section{Indocyanine Green Angiography}

Moulin et al. [17] reported a case illustrating proper tumour vascularization, but without any associated choroidal vessel dilatation (as in melanoma) or engorged retinal feeder vessels (as in retinal capillary haemangioma). In a recent study, most tumours revealed hypofluores- cence in all phases and none showing dual circulation [2]. However, dual circulation was reported in 2 cases in the study of Wei et al. [37].

\section{Optical Coherence Tomography}

It can be useful to assess posteriorly located tumours and the macular changes caused by the tumour like CME, ERM, exudates, and macular hole. Obtaining a good-quality images on optical coherence tomography (OCT) may be challenging due to the typical peripheral location of the tumour. Williams et al. [2] reported tumour-related features like high anterior tumour reflectivity, a Derby-hat appearance, posterior shadowing, retinal invasion, and optically empty cavities (in order of decreasing frequency). A case report by Mehta et al. [18] showed a minimal flow signal within an adenoma on OCT angiography. The adenoma was associated with CHRPE, causing subretinal fluid with exudates; the lack of an appreciable flow signal was useful to rule out a CNVM.

\section{Magnetic Resonance Imaging}

RPE tumours are reported to be hyperintense in T1 and hypointense in T2 [12,37]. Unfortunately, MRI may not differentiate RPE tumours from other tumours such as malignant melanoma or choroidal haemangioma since the imaging properties are similar [38]. MRI is done to rule out orbital extension and the rare possibility of intracranial metastases through local progression $[8,21,25$, 26].

\section{Metastatic Workup}

Usually, metastatic workup is done with an assumption of uveal melanoma, as in the case we have reported. IHC analysis of the biopsied/excised RPE tumour can give clues regarding the occult primary malignancy $[6,8]$.

\section{Fine-Needle Aspiration Biopsy}

Fine-needle aspiration biopsy (FNAB) is required where there is diagnostic uncertainty and a cytological analysis is needed for making a decision about therapy [3]. Disadvantages include diffusion of the tumour cells along the needle tract, intraocular bleeding and retina hole, inadequate material, and the need for experienced hands [37]. John and Lew [39] reported RPE adenomas displaying round cells with eccentrically placed nuclei and abundant granular cytoplasm with or without vacuolations. Usually, mild nuclear pleomorphism, rare mitoses, and large melanosomes are present. In cases with more cellular atypia, RPE adenocarcinoma may be 
considered [39]. However, cytology alone cannot differentiate between RPE adenomas and adenocarcinomas [39].

\section{Pathology}

One curious feature of RPE is its propensity to undergo reactive hyperplasia, which rarely assumes tumorous proportions with local invasion as in malignancy. Socalled true neoplasms, namely adenoma or even adenocarcinoma, rarely seems to metastasize.

\section{Gross Appearance}

The tumour appears deeply pigmented, sometimes amelanotic, with secondary retinal detachment and exudates (Fig. 1) [9, 32, 40, 41]. Usually, there is no extraocular extension.

\section{Histopathology}

The tumour consists of cuboidal/low columnar/polyhedral cells, contiguous with adjacent normal RPE [10, $20,32]$. One case report mentioned spindle-shaped cells [26]. The cells usually have abundant cytoplasm containing variable-sized melanin granules, exhibit mild nuclear pleomorphism, and have prominent nucleoli and few mitoses $[16,21,24,39,41]$. The tumour cells usually rest on periodic acid Schiff (PAS)-positive extracellular matrix $[17,18,33,34,37]$. Tso and Albert [1] described 4 patterns in which the tumour cells may be arranged, namely, mosaic (resembling normal RPE), tubular, a patternless arrangement of vacuolated cells, and a patternless arrangement of anaplastic cells. Tumours arising from the anterior RPE (and ciliary body) tend to have a vacuolated pattern, and those located posteriorly show a glandular or tubular configuration [2, 37, 39]. Font et al. [42] discovered by means of histochemistry that secretory intracellular vacuoles of tumour cells contained sialomucin; they hence stated the possibility of normal RPE contributing a small quantity of sialomucin to the inter-receptor mucoid.

Almost all the reported cases had retinal invasion with or without choroidal, vitreous, and optic-nerve head invasion. A few cases of inflammatory infiltrate (especially plasma cells) in the choroid have been reported in the setting of adenoma associated with CHRPE [16], but no nevoid cells as in melanoma. Since the tumour is situated internally (towards the retinal side) to Bruch's membrane, vitreous invasion is more common with RPE tumours than with melanoma [3]. Optic-nerve head invasion up to the lamina cribrosa is noted in many cases, especially if the tumour is juxta-papillary in location [1,
$3,6,10,34]$. Pre-laminar invasion of the optic nerve, along with extraocular extension along the emissary veins, was reported by Loeffler et al. [26]. Heindl et al. [8] reported aggressive RPE adenocarcinoma with invasion of the orbital optic-nerve head and subarachnoid space. Several cases of bone formation [43] and focal calcific degeneration [34] have been reported with these tumours.

\section{Electron Microscopy}

Electron microscopy shows tight junctions between the tumour cells and apical microvilli with mature and large melanosomes [12, 32, 42]. Font et al. [42] described 2 types of tumour cells seen on electron microscopy, namely, light and dark cells. The dark tumour cells had more rough endoplasmic reticulum (metabolically active), with large intracytoplasmic vacuoles displacing the pigment granules to one side of the cells, thus appearing dark. The light tumour cells did not contain vacuoles and showed a more even distribution of the melanin granules.

\section{Immunohistochemistry}

RPE tumours can co-express both epithelial markers and melanocytic markers [41]. Most of the studies reported that RPE tumours show positive immunoreactivity to epithelial markers (CAM 5.1, CK-AE1/AE3, EMA), vimentin, smooth muscle actin (SMA), neuron-specific enolase (NSE), and variable positivity for melanocyte markers (S-100, HMB-45, and Melan-A) [2, 3, 39]. All the tumours in the series by Williams et al. [2] showed positive immunoreactivity for CAM 5.2, CK-AE1/AE3, and CK-7, and most of them were positive for vimentin. Of note, there was a high rate of expression of uveal melanocyte-associated markers, namely S-100 (67\%), Melan-A (44\%) and HMB-45 (22\%). This highlights the IHC overlap between uveal melanoma and RPE tumours. Adenocarcinomas are often difficult to differentiate from adenomas histologically and clinically [34]. Indices of cell proliferation like MIB-1 and Ki-67 have been used to grade adenocarcinoma, i.e., as low- or high-grade [10, 41]. Sometimes, IHC markers like AFP, CEA9, and TTF1 can be used to rule out metastases, especially in the setting of an unsuspected tumour post-evisceration/enucleation [8].

\section{Differential Diagnosis}

The most important differential diagnosis in the case of a predominantly pigmented tumour is malignant melanoma. The clinical and imaging features that help to dif- 
Table 1. Features differentiating RPE tumours from posterior uveal melanoma

\begin{tabular}{|c|c|c|}
\hline Feature & RPE tumours $[2-4,9,20,39,41,42]$ & Melanoma $[39,44-46]$ \\
\hline $\begin{array}{l}\text { Clinical } \\
\text { (overlap is common) }\end{array}$ & $\begin{array}{l}\text { Abruptly elevated } \\
\text { Deeply pigmented } \\
\text { Underlying CHRPE }+/- \\
\text { Retinal feeding artery and draining vein present } \\
\text { Subretinal exudates more than exudative retinal } \\
\text { detachment }\end{array}$ & $\begin{array}{l}\text { Dome-shaped/collar-button configuration } \\
\text { Varied pigmentation } \\
\text { Closer to optic disc } \\
\text { Surface changes: orange pigment } \\
\text { Retinal draining vein present but no artery } \\
\text { Exudative retinal detachment more than subretinal exudates }\end{array}$ \\
\hline Fluorescein angiography & $\begin{array}{l}\text { Early hypofluorescence and late hyperfluorescence with } \\
\text { leakage and staining } \\
\text { Dual circulation absent }\end{array}$ & $\begin{array}{l}\text { Gradually increasing fluorescence that starts in the arterial } \\
\text { phase, increases in intensity well into the recirculation phase, } \\
\text { and persists for at least } 45 \mathrm{~min} \text {. } \\
\text { Dual circulation present }\end{array}$ \\
\hline Histopathology & $\begin{array}{l}\text { Low cuboidal/columnar cells with tubulo-acinar pattern, } \\
\text { vacuoles }+/- \text {, mature and large melanosomes, and mild } \\
\text { nuclear pleomorphism. } \\
\text { Tumour contiguous with RPE }\end{array}$ & $\begin{array}{l}\text { Spindle-shaped/epithelioid cells in the choroid, high nuclear } \\
\text { pleomorphism, frequent mitoses, and coarse chromatin with } \\
\text { fine-to-coarse pigment granules }\end{array}$ \\
\hline Immunohistochemistry & $\begin{array}{l}\text { Positive for epithelial markers (CAM 5.2, EMA, } \\
\text { CK-AE1/AE3, CK-8/18, CK-7), vimentin, NSE, SMA; } \\
\text { weakly positive for melanocytic markers }\end{array}$ & $\begin{array}{l}\text { Positive for S-100, HMB- } 45 \text {, SOX-10, and Melan-A, but } \\
\text { negative or weakly positive for epithelial markers }\end{array}$ \\
\hline Ultrasound & $\begin{array}{l}\text { Abruptly elevated or Derby-hat appearance, sometimes } \\
\text { dome-shaped } \\
\text { High internal reflectivity with acoustic solidity }\end{array}$ & $\begin{array}{l}\text { Collar button or mushroom shaped } \\
\text { Low internal reflectivity with acoustic hollowing }\end{array}$ \\
\hline Local invasion & $\begin{array}{l}\text { Retinal, vitreous, and choroidal invasion is common } \\
\text { Rare: optic nerve head. } \\
\text { Very rare: extraocular extension }\end{array}$ & Retinal and extraocular invasion \\
\hline Metastatic potential & Extremely low & $\begin{array}{l}\text { High risk for liver and lung; micro-metastases are quite } \\
\text { common }\end{array}$ \\
\hline
\end{tabular}

ferentiate RPE tumours from choroidal melanoma are presented in Table 1. Despite these differences, it is often difficult to differentiate them due to the clinical overlap, similar to the case described here. Due to the high malignant potential and the risk of micro-metastatic dormancy, a patient diagnosed as having uveal melanoma must be followed up for their entire life, irrespective of the size of the melanoma and the treatment received [45]. In contrast, such surveillance is not needed for RPE tumours [32]. Other simulating lesions are listed in Table 2, along with salient differentiating features.

\section{Clinical Course and Prognosis}

Most RPE tumours grow, albeit slower than melanoma. Small asymptomatic tumours can remain stable or enlarge very slowly over a period with a good visual outcome; Loose et al. [34] reported on an RPE tumour which remained stable for 15 years. RPE adenoma and adenocarcinoma are difficult to differentiate both clinically and on histopathology [35]. Although named as adenocarcinoma, adenoma is locally invasive and has less malignant potential [15]. Based on proliferative indices and cellular pleomorphism, one can differentiate RPE adenoma from adenocarcinoma $[10,39,41]$. However, the implications for prognosis still need to be elucidated.

Adenocarcinomas of the RPE with extrascleral extension may be capable of metastasis $[20,22]$. Absence of extraocular extension at the time of enucleation makes the prognosis appear to be excellent [20]. Loeffler et al. [26] reported extraocular extension along the emissary vein from choroidal invasion, noted in an enucleated painful blind eye; the patient did well after 1 year of follow-up and had no metastatic disease. Another case of aggressively metastasising RPE adenocarcinoma was reported by Heindl et al. [8]; the painful blind eye with opaque media was enucleated under suspicion of intraocular tumour based on ultrasound. Histopathology revealed a poorly differentiated epithelial tumour in the posterior vitreous cavity and invading the choroid, sclera, 
Table 2. Differential diagnoses of RPE adenoma/adenocarcinoma other than uveal melanoma

\begin{tabular}{|c|c|}
\hline RPE hyperplasia [46] & $\begin{array}{l}\text { Differentiation is difficult } \\
\text { There is a history of previous eye disease or trauma }\end{array}$ \\
\hline Uveal metastasis [6] & $\begin{array}{l}\text { Metastatic workup } \\
\text { Immunohistochemistry of the tumour specimen for markers of occult primary tumour }\end{array}$ \\
\hline Melanocytoma [34] & $\begin{array}{l}\text { Smooth velvety, jet-black appearance } \\
\text { Typically, juxta-papillary location with fibrillated borders } \\
\text { Can cause secondary glaucoma } \\
\text { Carries a } 1-2 \% \text { risk for malignant transformation }\end{array}$ \\
\hline Choroidal neovascularization [31] & $\begin{array}{l}\text { Dye-based or OCT angiography can highlight the membrane } \\
\text { Underlying aetiology drives disease activity }\end{array}$ \\
\hline $\begin{array}{l}\text { CHRRPE } \\
\text { (combined hamartoma of the retina } \\
\text { and retinal pigment epithelium) [44] }\end{array}$ & $\begin{array}{l}\text { Usually solitary and unilateral lesions located at the posterior pole; typically, slightly elevated, ill-defined grey- } \\
\text { ish-orange retinal mass with varying amounts of pigmentation, vascular tortuosity, and epiretinal membrane } \\
\text { formation } \\
\text { Saw-tooth appearance on OCT } \\
\text { Associated with neurofibromatosis in some cases } \\
\text { Histopathology shows proliferating glial tissue and blood vessels }\end{array}$ \\
\hline $\begin{array}{l}\text { PEHCR } \\
\text { (peripheral exudative haemorrhagic } \\
\text { chorioretinopathy) [47] }\end{array}$ & $\begin{array}{l}\text { Clinically appears as a homogenous deep-brown mass in the periphery with exudative and haemorrhagic } \\
\text { changes } \\
\text { Shows blockage on fundus fluorescein angiography } \\
\text { Ultrasound shows echo-density with retraction cleft }\end{array}$ \\
\hline
\end{tabular}

orbital optic nerve, and subarachnoid space. As orbital CT and MRI showed a thickened intraorbital optic nerve, eyelid-sparing exenteration and frontotemporal craniotomy were performed for microscopically controlled excision of the optic nerve anterior to the chiasm, followed by stereotactic radiotherapy. Five months later, several intracerebral metastatic foci were noted by means of lumbar tap that revealed tumour cells in the cerebrospinal fluid. The patient died 14 months after enucleation due to pulmonary embolism, despite palliative craniospinal radiation. Lemaitre et al. [25] reported a case of unsuspected pigment epithelium adenocarcinoma with the dissemination of tumour cells in the orbit following evisceration, with local progression to the brain and the death of the patient. Systemic metastatic workup was negative in this patient.

\section{Visual Outcome}

RPE tumours can cause loss of vision loss due to macular exudates, exudative retinal detachment (large tumours), and, rarely, subretinal gliosis [3, 5, 9, 15]. Even peripheral tumours can cause reduced vision due to remote macular changes like CME, surface-wrinkling maculopathy, and macular hole [19]. Williams et al. [2] found that the factors predicting poor visual prognosis include poor baseline visual acuity and exudative retinal detachment (suggesting a large and aggressive tumour). In contrast, the absence of retinal feeder vessels was predictive of good visual outcome. Multiple treatment was associated with tumour growth indicating resistance to therapy. The overall visual outcome was variable.

\section{Management}

Observation

Observation is the most suitable management for small, asymptomatic lesions [2]. If melanoma is ruled out, a periodic check-up with proper photographic documentation (preferably ultrawide imaging for peripheral tumours) will suffice in most of cases. Treatment needs to be considered when lipid exudates appear.

\section{Radiotherapy}

There have been many reports of RPE tumours being treated with radiotherapy under the assumption of melanoma, with limited success. The patients did not have good visual outcomes and had to undergo enucleation, most often due to the progressive growth of the tumour which caused exudative detachment, in addition to complications associated with radiotherapy $[14,22,30]$. It has now been acknowledged that RPE tumours are not very 
radiosensitive. In a case reported by Finger et al. [22] (assumed to be melanoma), enucleation was done after radiotherapy failed. Moulin et al. [17] treated a case of RPE adenocarcinoma arising from CHRPE with proton-beam therapy. They first treated the pigmented tumour with proton therapy followed by vitrectomy with ab-interno tumorectomy, to avoid toxic tumour syndrome, in order to establish a tissue diagnosis and determine the oncologic follow-up.

\section{Local Resection}

Local resection can be approached through exo- or endoresection. Exoresection via partial lamellar sclerouvectomy (PLSU) is technically difficult and associated with more complications in these tumours than for melanoma due to retinal invasion [2]. Hence, this technique may be best reserved for lesions anterior to the equator with documented growth or exudative changes threatening loss of vision [2]. The procedure is done after performing prophylactic laser coagulation to the posterior margins of the tumour $[14,15]$. Williams et al. [2] showed in their series that none of the eyes had a recurrence or needed enucleation post-PLSU. Two reports of RPE adenocarcinoma from CHRPE, managed with trans-scleral resection also did well $[14,15]$. Endoresection via pars plana vitrectomy for RPE tumours was reported by Wei et al. [37] in 3 patients for RPE adenoma, with good results.

\section{Enucleation}

Enucleation is still considered to be the gold standard treatment [2]. The most common indication for enucleation has been the diagnostic dilemma with melanoma [2]. Often, the diagnosis of RPE tumours is made after histopathological analysis of the tumour specimen. Tumours arising from the posterior pole and total exudative retinal detachment with grim visual prognosis are also indications for enucleation. Factors associated with enucleation include large tumour size and exudative retinal detachment [2].

\section{Other Treatment Options}

There are a few reports of RPE tumours being treated by argon green laser and photodynamic therapy, but with inconsistent results [2]. The patients needed some form of secondary treatment like PLSU or enucleation. In Mehta et al. [18], the patient received 6 intravitreal bevacizumab injections for macular exudation caused by CHRPE-associated adenoma. They reported a good response with improved BCVA and tumour regression; however, there was no long-term follow-up.

\section{Conclusion}

True acquired neoplasms of the RPE, namely, adenoma and adenocarcinoma, are rare pigmented tumours that often simulate posterior uveal melanoma [48-50]. They can be differentiated from melanoma by their clinical, imaging, and cytopathological features. A definitive diagnosis is established by histopathology along with IHC analysis. RPE tumours are locally invasive with a low metastatic potential, and they carry a better prognosis than melanoma. Small, asymptomatic tumours can be observed at periodic intervals, and peripheral tumours amenable to surgery can be managed with local resection. Enucleation is needed for large tumours with exudative retinal detachment, or when melanoma cannot be ruled out.

\section{Statement of Ethics}

The patient who was the subject of the case report included in this paper gave his informed consent.

\section{Conflict of Interest Statement}

The authors declare that they have no conflicts of interest to disclose.

\section{Funding Sources}

Authors did not receive grant support or research funding.

\section{Author Contributions}

J.S.: literature searches, analysis of data, wrote the first draft, manuscript revision. P.R.: substantial contributions to the conception or design of the work, Literature searches, analysis of data, interpretation of data, revising manuscript critically for important intellectual content. K.D.: analysis of data, interpretation of data, critical review of the manuscript. K.S.: critical review of the manuscript, with contributions to pathological aspects. J.B.: critical review of the manuscript, with contributions to pathological aspects. All authors approved of the final version as submitted. 


\section{References}

1 Tso MO, Albert DM. Pathological condition of the retinal pigment epithelium. Neoplasms and nodular non-neoplastic lesions. Arch Ophthalmol. 1972 Jul;88(1):27-38.

2 Williams BK Jr, Di Nicola M, Acaba-Berrocal LA, Milman T, Mashayekhi A, Lucio-Alvarez JA, et al. Adenoma and Adenocarcinoma of the Retinal Pigment Epithelium: A Review of 51 Consecutive Patients. Ophthalmol Retina. 2020 Aug;4(8):829-39.

3 Shields JA, Shields CL, Gündüz K, Eagle RC Jr. Neoplasms of the retinal pigment epithelium: the 1998 Albert Ruedemann, Sr, memorial lecture, Part 2. Arch Ophthalmol. 1999 May;117(5):601-8.

4 Williams BK Jr, Di Nicola M, Lucio-Alvarez JA, Lally DR, Shields CL. Choroidal Melanoma Simulating Adenoma of the Retinal Pigment Epithelium Arising at the Site of Congenital Hypertrophy of the Retinal Pigment Epithelium. Ocul Oncol Pathol. 2020 Jan; 6(1):39-43.

5 Saeed MU, Chang BY, Anand S, Chakrabarty A. Diagnostic surprise in an evisceration specimen. Orbit. 2007 Jun;26(2):129-31.

6 Adulkar N, Radhakrishnan S, Vidhya N, Kim U. RPE Adenocarcinoma as the Presenting Sign of Bronchogenic Carcinoma: Diagnostic Dilemma in the Management of a Case. Case Rep Ophthalmol Med. 2013;2013:786378.

7 Alkatan HM, Al Qahtani AA, Maktabi AM. Intraocular adenocarcinoma: histopathological report of two cases with different origin. Can J Ophthalmol. 2016 Apr;51(2):e67-70.

8 Heindl LM, Naumann GO, Kruse FE, Holbach LM. Aggressive metastasising adenocarcinoma of the retinal pigment epithelium with trisomy 21. Br J Ophthalmol. 2008 Mar; 92(3):389-91.

9 Ramahefasolo S, Soubrane G, Dhermy P, Godel V, Regenbogen L, Coscas G. Adenocarcinoma of retinal pigment epithelium. Br J Ophthalmol. 1987 Jul;71(7):516-20.

10 Sommacal A, Campbell RJ, Helbig H. Adenocarcinoma of the retinal pigment epithelium. Arch Ophthalmol. 2003 Oct;121(10):1481-3.

11 Guerin EP, Wong D, Silvestri G, Hiscott PS Cytokeratin subtyping to distinguish reactive and neoplastic RPE cells. Br J Ophthalmol. 2006 Jun;90(6):801-2.

12 Mori H, Takahashi K. A Case of Adenocarcinoma of the Retinal Pigment Epithelium: An Immunohistochemical and Electron Microscopic Study. Ocul Oncol Pathol. 2017 Dec; 4(1):38-43.

13 Shields JA, Shields CL, Singh AD. Acquired tumors arising from congenital hypertrophy of the retinal pigment epithelium. Arch Ophthalmol. 2000 May;118(5):637-41.

14 Shields JA, Shields CL, Eagle RC Jr, Singh AD. Adenocarcinoma arising from congenital hypertrophy of retinal pigment epithelium. Arch Ophthalmol. 2001 Apr;119(4):597-602.
15 Trichopoulos N, Augsburger JJ, Schneider S. Adenocarcinoma arising from congenital hypertrophy of the retinal pigment epithelium. Graefes Arch Clin Exp Ophthalmol. 2006 Jan; 244(1):125-8.

16 Shields JA, Eagle RC Jr, Shields CL, Brown GC, Lally SE. Malignant transformation of congenital hypertrophy of the retinal pigment epithelium. Ophthalmology. 2009 Nov; 116(11):2213-6.

17 Moulin AP, Zografos L, Schalenbourg A. RPE adenocarcinoma arising from a congenital hypertrophy of the RPE (CHRPE) treated with proton therapy. Klin Monatsbl Augenheilkd. 2014 Apr;231(4):411-3.

18 Mehta N, Gal-Or O, Barbazetto I, Modi Y, Shields CL, Freund KB. Atypical congenital hypertrophy of the retinal pigment epithelium complicated by presumed retinal pigment epithelial adenoma and exudative maculopathy. Retin Cases Brief Rep. 2018; DOI: 10.1097/ICB.0000000000000800.

19 Shields JA, Shields CL, Slakter J, Wood W, Yannuzzi LA. Locally invasive tumors arising from hyperplasia of the retinal pigment epithelium. Retina. 2001;21(5):487-92.

20 Garner A. Tumours of the retinal pigment epithelium. Br J Ophthalmol. 1970 Nov;54(11): 715-23.

21 Palamar M, Shields CL, Marr BP, Eagle RC Jr, Shields JA. Retinal pigment epithelial tumor in a young Asian female. Eur J Ophthalmol. 2009 May-Jun;19(3):487-9.

22 Finger PT, McCormick SA, Davidian M, Walsh JB. Adenocarcinoma of the retinal pigment epithelium: a diagnostic and therapeutic challenge. Graefes Arch Clin Exp Ophthalmol. 1996 Aug;234(1 Suppl 1):S22-7.

23 Shields CL, Mashayekhi A, Ho T, Cater J, Shields JA. Solitary congenital hypertrophy of the retinal pigment epithelium: clinical features and frequency of enlargement in $330 \mathrm{pa}-$ tients. Ophthalmology. 2003 Oct;110(10): 1968-76.

24 Shields JA, Eagle RC Jr, Barr CC, Shields CL, Jones DE. Adenocarcinoma of retinal pigment epithelium arising from a juxtapapillary histoplasmosis scar. Arch Ophthalmol. 1994 May;112(5):650-3.

25 Lemaitre S, Lecler A, Lévy-Gabriel C, Reyes C, Desjardins L, Gentien D, et al. Evisceration and ocular tumors: what are the consequences? J Fr Ophtalmol. 2017 Feb;40(2):93-101.

26 Loeffler KU, Kivelä T, Borgmann H, Witschel $\mathrm{H}$. Malignant tumor of the retinal pigment epithelium with extraocular extension in a phthisical eye. Graefes Arch Clin Exp Ophthalmol. 1996 Aug;234(Suppl 1):S70-5.

27 Edelstein C, Shields CL, Shields JA, Eagle RC Jr. Presumed adenocarcinoma of the retinal pigment epithelium in a blind eye with a staphyloma. Arch Ophthalmol. 1998 Apr; 116(4):525-8.
28 Roelofs K, Kherani F, Russell L, Heathcote JG, Weis E. Adenocarcinoma of the Retinal Pigment Epithelium Arising in Conjunction with Late Recurrence and Systemic Metastasis of Retinoblastoma. Ocul Oncol Pathol. 2017 Nov;3(4):296-300.

29 Fiorentzis M, Heimann H, Thornton S, Coupland SE. Two different tumours in the same eye. Clin Exp Ophthalmol. 2017 Apr;45(3): 299-301.

30 Nakamura S, Hikita N, Yamakawa R, Moriya F, Yano H, Furusato E, et al. A clinically challenging diagnosis of adenoma of the retinal pigment epithelium presenting with clinical features of choroidal hemangioma. Clin Ophthalmol. 2012;6:497-502.

31 Shields JA, Materin M, Shields CL, Eagle RC Jr. Adenoma of the retinal pigment epithelium simulating a juxtapapillary choroidal neovascular membrane. Arch Ophthalmol. 2001 Feb;119(2):289-92.

32 Minckler D, Allen AW Jr. Adenocarcinoma of the retinal pigment epithelium. Arch Ophthalmol. 1978 Dec;96(12):2252-4.

33 Shields JA, Eagle RC Jr, Shields CL, De Potter P. Pigmented adenoma of the optic nerve head simulating a melanocytoma. Ophthalmology. 1992 Nov;99(11):1705-8.

34 Loose IA, Jampol LM, O'Grady R. Pigmented adenoma mimicking a juxtapapillary melanoma. A 20-year follow-up. Arch Ophthalmol. 1999 Jan;117(1):120-2.

35 Cupp DG, McCannel TA. Macular pucker in association with RPE adenoma: a report of a case and review of the literature. Semin Ophthalmol. 2014 Jul;29(4):199-201.

36 Penna D, Schmidt A, Beermann F. Tumors of the retinal pigment epithelium metastasize to inguinal lymph nodes and spleen in tyrosinase-related protein $1 / \mathrm{SV} 40 \mathrm{~T}$ antigen transgenic mice. Oncogene. 1998 Nov; 17(20): 2601-7.

37 Wei W, Mo J, Jie Y, Li B. Adenoma of the retinal pigment epithelium: a report of 3 cases. Can J Ophthalmol. 2010 Apr;45(2):166-70.

38 Yaman A, Lebe B, Kiratli H, Saatci I, Soylev MF, Saatci AO. Adenoma of the retinal pigment epithelium mimicking ciliochoroidal melanoma. Clin Exp Optom. 2009 Mar;92(2): 157-8.

39 John S, Lew M. Retinal pigment epithelium adenoma in vitreous fluid cytology. Diagn Cytopathol. 2017 Dec;45(12):1128-31.

40 Fan JT, Robertson DM, Campbell RJ. Clinicopathologic correlation of a case of adenocarcinoma of the retinal pigment epithelium. Am J Ophthalmol. 1995 Feb;119(2):243-5.

41 Shields JA, Eagle RC Jr, Dutton J, Ehya H, Shields CL. Adenocarcinoma of the retinal pigment epithelium: clinicopathologic correlation with paradoxical immunohistochemical findings. JAMA Ophthalmol. 2014 Oct; 132(10):1249-52. 
42 Font RL, Zimmerman LE, Fine BS. Adenoma of the retinal pigment epithelium: histochemical and electron microscopic observations. Am J Ophthalmol. 1972 Apr;73(4):544-54.

43 Graham GC. Juxtapapillary retinal pigment epithelial tumor. Adenocarcinoma vs reactive hyperplasia. Arch Ophthalmol. 1971 Mar; 85(3):299-301.

44 Shields JA, Shields CL. Intraocular tumour, atlas and textbook. 3rd ed. Philadelphia: Lippincott Williams \& Wilkins; 2016.
45 Nichols EE, Richmond A, Daniels AB. Micrometastatic Dormancy in Uveal Melanoma: A Comprehensive Review of the Evidence, Mechanisms, and Implications for Future Adjuvant Therapies. Int Ophthalmol Clin. 2017;57(1):1-10.

46 Heegaard S, Larsen JN, Fledelius HC, Prause JU. Neoplasia versus hyperplasia of the retinal pigment epithelium. A comparison of two cases. Acta Ophthalmol Scand. 2001 Dec; 79(6):626-33.

47 Shields CL, Salazar PF, Mashayekhi A, Shields JA. Peripheral exudative hemorrhagic chorioretinopathy simulating choroidal melanoma in 173 eyes. Ophthalmology. 2009 Mar; 116(3):529-35.
48 Shields JA, Shields CL. Tumors and Related Lesions of the Pigmented Epithelium. Asia Pac J Ophthalmol (Phila). 2017 Mar-Apr; 6(2):215-23

49 Fair JR. Tumors of the retinal pigment epithelium. Am J Ophthalmol. 1958 Apr;45(4 Pt 1): 495-505.

50 Asadi AF, Moradi H, Rajabi MT, Riazi EM. Adenocarcinoma of Retinal Pigment Epithelium Clinically Diagnosed as Malignant Melanoma; A Case Report with Unsystematic Review of Literature. J Curr Ophthalmol. 2007; 19(4):43-47. 